\title{
Nötrofil-Lenfosit Oranı Vasküler Behçet Hastalığı için Yeni Bir Belirteç Olabilir mi?
}

\author{
May Neutrophil-Lymphocyte Ratio Be A New Marker for Vascular Behcet Disease?
}

${ }^{1}$ Eskişehir Osmangazi Üniversitesi, Romatoloji Bilim Dalı, Eskişehir,

Türkiye
${ }^{2}$ Eskişehir Osmangazi Üniversitesi, Biyoistatistik Anabilim Dalı, Eskișehir, Türkiye

Correspondence: Nazife Sule YAŞAR- Eskişehir Osmangazi Üniversitesi, Romatoloji Bilim Dalı, Eskişehir, Türkiye e-mail:suleyasar@yahoo.com Received: 11.05 .2020 Accepted: 15.06.2020

Online published: 23.06 .2020

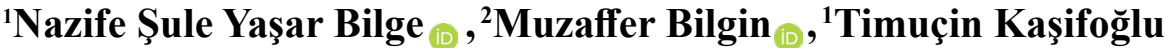

\begin{abstract}
Özet
Behçet hastalığı, tekrarlayan oral ve genital ülserler, üveit ve tipik cilt lezyonları ile bilinen sistemik bir vaskülittir. Nötrofil-lenfosit oranı (NLO) inflamasyon göstergesi olarak kullanılması araştırılan bir belirteçtir ve özellikle sub-klinik inflamasyon belirteci olarak kabul edilmektedir.Bu çalışmanın amacı vasküler ve mukokutanöz tutulumu olan Behçet hastalarında NLO'nun değerlendirilmesi ve sağlıklı kișilerden olușan kontrol grubu ile karşılaștırılmasıdır. Çalıșmaya tromboz öyküsü olan 20 Behçet hastası (Grup 1), mukokutanöz tutulumu olan 20 Behçet hastası (Grup 2) ve 20 sağlıklı gönüllü (Grup 3) dahil edildi.Hastaların dosyaları retrospektif incelendi, tam kan testindeki nötrofil ve lenfosit değerleri kullanılarak NLO aritmetik olarak hesaplandı. Yaş ve cinsiyet dağılımı gruplar arası fark göstermemekteydi (p: 0,416 ve p:0,442, sırasıyla). Tam kan sayımı parametreleri değerlendirildiğinde Grup 1'in hemoglobin değeri en düşük, lökosit ve mutlak nötrofil değerleri en yüksekti (p:0,045,p:0,033 ve p:0,003, sırasıyla). Grup 1'in NLO' nun diğer iki gruba göre yüksek olduğu, Grup 2 ve 3 arasında fark olmadığ 1 saptandı. (p:0,016; çoklu analizde 1 vs 2; p:0,009, 1 vs 3; p:0,018,1 vs 3; p:0,807). Grup 1'de NLO ile hastalık aktivitesi ve şiddeti arasındaki ilişki incelendiğinde korelasyon saptanmadı (aktivite için: r:-0,212, p: 0,370 ve şiddet için r: -0,223, p: 0.344, sırasıyla). C-RP ile NLO korelasyonu sadece Grup 1'de saptanırken (r: 0,634, p: $0,03$ ) hiçbir grupta ESH ile NLO korelasyonu saptanmadı ( $p>0,05)$. Sonuç olarak,NLO'nuntrombozu olan Behçet hastalarında mukokutanöztutulumlu olanlara veya sağlıklı kontrollere göre artmış olduğunu gösterdik. NLO, Behçet hastalığı gibi spesifik bir laboratuar göstergesi olmayan durumlarda artmış inflamasyonu veya hastalık aktivitesini değerlendirmede faydalı olabilir.
\end{abstract}

Anahtar Kelimeler: Behçet hastalığı, nötrofillenfosit oranı, vasküler tutulum, hastalık aktivitesi

\section{Abstract}

Behcet disease is a system icvas culitis characterize dbyre current oral andgenitalul ceration, uveitisand cutaneouslesions. Neutrophil-lymphocyteratio (NLR) is a new marker investigatedforindi catingin flammation. Ouraim in this study was to evaluate NLR in Behcet patients with vascularand mucocutaneusin volvementand to compare with healthy controls. This study included 20 Behcet patient swith thrombosis (Group 1), 20 Behcet patients with mucocutaneusin volvement (Group 2) and 20 healthy subjects (Group 3). Then eutrophiland lymphocytecounts of the patients in hemograms were used to calculate NLR. Ageand sex distribution did not showany difference among groups (p: 0.416and p:0.442, respectively). Hemoglobin levels was lowe stand leucocyte andabsolute neutrophil counts were highest in Group 1 (p:0.045,p:0.033 ve p:0.003, respectively). NLR washigher in Group 1than Group 2 and 3 (p:0.016; multi analysis results: 1 vs $2 ; \mathrm{p}: 0.009,1 \mathrm{vs} 3 ; \mathrm{p}: 0.018,1 \mathrm{vs} 3 ; \mathrm{p}: 0.807)$. NLR anddi sease activityands everity did not show correlation in Group 1 (foractivity: r:-0.212, p: 0.370 andforseverity r: -0.223 , p: 0.344 , respectively). The correlation between NLR and C-RP wasonly signifi cant in Group 1 ( $\mathrm{r}$ : 0.634, p: 0.03)but ESR did not showcorrelation in anygroup ( $>00.05$ ). Inconclusion, NLR washigher in Behcet patients with thrombosis than Behcet patients with mucocutaneusin volve mentand control group. NLR may be useful in situations with outany specific marker to determinein crease dinflammation or disease activitysuch as Behcet disease.

Keywords: Behcet disease, neutrophil-lymphocyteratio, vascularin volvement, disease activity 


\section{Giriș}

Behçet hastalığı (BH), tekrarlayan oral ve genital ülserler, üveit ve tipik cilt lezyonları ile karakterize sistemik bir vaskülittir. Ancak derin ventrombozu, serebral sinüs trombozu ve pulmoner arter anevrizması gibi diğer vasküler tutulum şekilleri mortalite ve morbiditeye katkısı olan önemli bulgulardır (1).

BH'da hastalık aktivitesini gösteren özel bir laboratuar testi yoktur. Ancak, interlökin (IL)-6, IL-1 $\beta$, tümör nekroz faktör (TNF)- $\alpha$, trombomodulin, e-selektin, vaskülerendotelyal büyüme faktörü (VEGF), total homosistein, $\alpha-1$ antitripsin, $\alpha-2$ makroglobulinin kullanılabileceği yönünde çalışmalar vardır (2).

Son yıllarda nötrofil-lenfosit oranı (NLO) inflamasyonun göstergesi olarak kullanılan bir markerdir.Genellikle sub-klinikinflamasyonungöstergesiolarakkabuledilmektedir. İnflamasyon durumunda nötrofil ve trombosit sayıları artarken lenfosit sayıları azalır (3).YapılançalışmalardaNLO'nunmorbiditevemortaliteninhesaplanmasındakullanılabileceğiyönündebulgularaulaşılmıştır. NLO diyabet, hipertansiyon, otoinflamatuar hastalık ve malignitelerdeinflamasyonun şiddetini göstermede kullanılmaya başlanmıştır. Çeşitli romatolojik hastalıklarda da NLO çalışılmış olup lupus nefritinde, romatoidartritte (RA) ve ankilozanspondilitte (AS) hastalık aktivitesi ile ilişkili olduğu saptanmıştır (3-5).

Bu çalışmada amacımız vasküler ve mukokutanöz tutulumu olan Behçet hastalarında NLO'nun değerlendirilmesi ve sağlıklı kişilerden oluşan kontrol grubu ile karşılaştırılmasidir.

\section{Gereç ve Yöntem}

Çalışmaya Uluslararası Çalışma Grubu'nun kriterlerine göre (6) BH tanısı almış 40 hasta ve 20 sağlıklı gönüllü dahil (Grup 3) edildi. BH'ların 20'sinin tromboz öyküsü vardı (Grup 1), 20'sinin de mukokutanöz tutulumu vardı (Grup 2).
Hastaların dosyaları retrospektif olarak incelendi. Yaş, cinsiyet, hastalık süresi, hemoglobin, lökosit ve platelet değerleri kaydedildi. Mukokutanöz tutulumu olan hastaların son kontroldeki tam kan sayımlarından, trombozu olan hastaların ise atak dönemindeki tam kan sayımlarından mutlak nötrofil ve mutlak lenfosit değerlerinin birbirine bölünmesi ile NLO aritmetik olarak hesapland. Bilindiği kadarıyla NLO için spesifik bir referans aralığı mevcut değildir.

Behçet hastalığı aktivite ve şiddeti BD Current Activity Form (BDCAF) ile değerlendirildi (7) ve NLO ile korelasyonuna bakıldı. BDCAF için hastalar klinik olarak değerlendirildi ve skoru 2 ve üzerinde olan hastalar aktif olarak kabul edildi (8). Cinsiyet, eritrosit sedimantasyon hızı (ESH) ve C-reaktif protein (C-RP) ile NLO ilişkisi değerlendirildi.

Çalışma Eskişehir Osmangazi Üniversitesi Girişimsel Olmayan Klinik Araştırmalar Etik Kurul Başkanlığg tarafından onayland1.

\section{Istatistik}

Sürekli veriler Ortalama \pm Standart Sapma olarak verilmiştir. Kategorik veriler ise yüzde (\%) olarak verilmiştir. Verilerin normal dağılıma uygunluğunun araştırılmasında ShapiroWilk testinden yararlanılmıştır. Normal dağılım gösteren grupların karşılaştırılmasında, grup sayısı iki olan durumlar için bağımsız örnek t testi analizi, grup sayısı üç ve üzerinde olan durumlar için tek yönlü varyans analizi (One-Way ANOVA) kullanılmıştır. Normal dağılıma uygunluk göstermeyen grupların karşılaştırılmasında grup sayısı üç ve üzerinde olan durumlar için Kruskal-Wallis $\mathrm{H}$ testi kullanılmıştır. Değişkenler arasındaki ilişkinin belirlenmesi için Pearson Korelasyon analizi kullanılmıştır. Oluşturulan çapraz tabloların analizinde Pearson Ki-Kare analizi kullanılmıştır. Analizlerin uygulanmasında IBM SPSS Statistics 21.0 (IBM Corp. Released 2012. IBM SPSS Statisticsfor Windows, Version 21.0. Armonk, NY: IBM Corp.) programından yararlanılmıştır. İstatistiksel önemlilik için $\mathrm{p}<0.05$ değeri kriter kabul edilmiştir. 


\section{Sonuçar}

Tromboz öyküsü olan BH grubunda (Grup 1) yaş ortalaması 43,55 $\pm 8,31$, mukokutanöz tutulumu olan BH'larında (Grup 2) yaş ortalaması 46,85 $\pm 9,43$ ve kontrol grubunun yaş ortalaması (Grup 3) 41,65 $\pm 6,54$ y1l idi; gruplar arasında istatistiksel olarak fark yoktu (p:0,416).

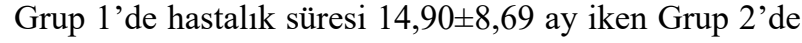
hastalık süresi 11,30 $\pm 8,80$ ay idi; gruplar arası fark yoktu (p: 0,201). Her 3 grubun kadın/erkek oranları benzerdi $(9 / 11 ; 12 / 8 ; 14 / 6 ; p: 0,442)$. Hastaların ortalama yaş, cinsiyet dağılımı ve hastalık süreleri Tablo 1'de özetlenmiştir.

Tablo 1. Hastaların ortalama yaş, cinsiyet dağılımı ve hastalık süreleri

\begin{tabular}{|c|c|c|c|c|c|}
\hline & & Grup 1 & Grup 2 & Grup 3 & $\mathbf{p}$ \\
\hline Yaş (me: & d sapma)(yıl) & $43,55 \pm 8.31$ & $46,85 \pm 9,43$ & $41,65 \pm 6.54$ & 0,416 \\
\hline \multicolumn{6}{|c|}{ sapma)(ay) } \\
\hline \multirow[t]{2}{*}{ Cinsiyet } & Kadın [n (\%)] & $9(\% 45.0)$ & $12(\% 60.0)$ & $14(\% 70.0)$ & \multirow[t]{2}{*}{0,442} \\
\hline & Erkek [n(\%)] & $11(\% 55.0)$ & $8(\% 40.0)$ & $6(\% 30.0)$ & \\
\hline
\end{tabular}

Gruplar arası tam kan sayımı değerleri, eritrosit sedimantasyon hizı (ESH) ve C-reaktif protein (C-RP) değerleri karşılaştırıldı. Grup 1'in ortalama hemoglobin değeri $(12,96 \pm 1,30 \mathrm{mg} / \mathrm{dL})$, Grup $2(14,06 \pm 1,60)$ ve Grup 3'ten $(13,81 \pm 1,35)$ düşüktü (p:0,045). Grup 3'ün lökosit $(7,00 \pm 1,69 \times 103 \mathrm{ru} / \mathrm{L})$ ve mutlak nötrofil sayısı $(4,03 \pm 1,36 \times 1031 \mathrm{u} / \mathrm{L})$,

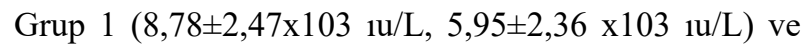

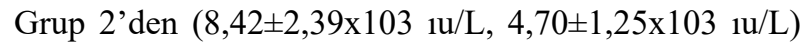
düşüktü (p:0,033 ve p:0,003,sırasıyla). Mutlak lenfosit, trombosit, ESH ve C-RP değerleri karşılaştırıldığında gruplar arası bir fark saptanmadı (sırasıly p:0;713, p:0,849, p:0,107 ve p:0,056) (Tablo 2).

Tablo 2. Grupların hematolojik parametrelerinin ve ESH, C-RP değerlerinin ortalaması

\begin{tabular}{|c|c|c|c|c|c|}
\hline Hemoglobin (mg/dL) & Grup 1 & Grup 2 & Grup 3 & $\mathbf{p}$ & $\begin{array}{c}\text { Çoklu } \\
\text { Analiz } \\
\text { p }\end{array}$ \\
\hline & $12,96 \pm 1,30$ & $14,06 \pm 1,60$ & $13,81 \pm 1,35$ & 0,045 & $\begin{array}{l}\text { 1vs2: } \mathbf{0 , 0 1 7} \\
\text { 1vs3: } \mathbf{0 , 0 2 5} \\
\text { 2vs3: } 0,051\end{array}$ \\
\hline Lökosit (x10 ${ }^{3}$ Iu/L) & $8,78 \pm 2,47$ & $8,42 \pm 2,39$ & $7,00 \pm 1,69$ & $\mathbf{0 , 0 3 3}$ & $\begin{array}{l}\text { 1vs2: } 0,051 \\
\text { 1vs3: } \mathbf{0 , 0 1 7} \\
\text { 2vs3: } \mathbf{0 , 0 2 5}\end{array}$ \\
\hline ANS $\left(x 10^{3} \mathrm{lu} / \mathrm{L}\right)$ & $5,95 \pm 2,36$ & $4.70 \pm 1.25$ & $4,03 \pm 1,36$ & 0,003 & $\begin{array}{l}\text { 1vs2: } \mathbf{0 , 0 2 5} \\
\text { 1vs3: } \mathbf{0 , 0 1 7} \\
\text { 2vs3: } 0,050\end{array}$ \\
\hline $\operatorname{ALS}\left(x_{10}^{3} \mathrm{lu} / \mathrm{L}\right)$ & $2,03 \pm 0,63$ & $2.16 \pm 0.43$ & $2,20 \pm 0,90$ & 0,713 & - \\
\hline Trombosit (x10 ${ }^{3}$ 1u/L) & $261,05 \pm 68,05$ & $250.25 \pm 70.05$ & $260,40 \pm 62,47$ & 0,849 & - \\
\hline ES H (mm/sa) & $28,35 \pm 25,25$ & $17,80 \pm 15,72$ & $16,90 \pm 12,62$ & 0,107 & - \\
\hline C-RP (mg/dl) & $3,52 \pm 6,34$ & $1,07 \pm 0,96$ & $0,96 \pm 0,66$ & 0,056 & - \\
\hline
\end{tabular}




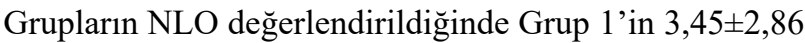
[2,54(2,04-4,29)], Grup 2'nin 2,04 $\pm 0,99$ [1,80(1,36$2,55)]$ ve Grup 3'ün 2,04 $\pm 0,083$ [1,90(1,58-2,66)] olarak saptand. Grup 1'in NLO'nındiğer iki gruba göre yüksek olduğu, Grup 2 ve 3 arasında fark olmadığ saptand. (p:0,016; çoklu analizde 1 vs 2 p:0,009, 1 vs 3 p:0,018, 1 vs 3 p:0.807) (Tablo 3).

Tablo 3. Grupların NLO'nın karşılaştırılması

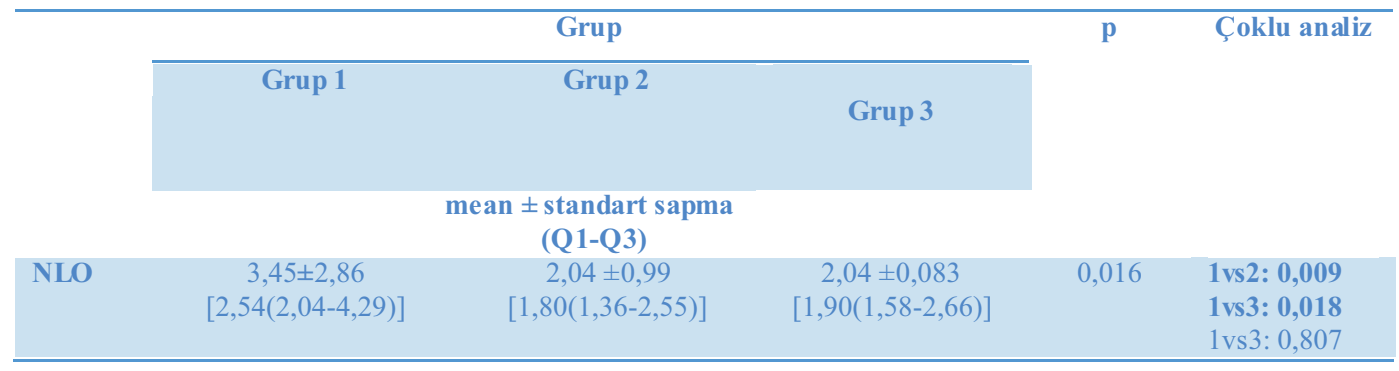

Trombozu olan hasta grubunda (Grup 1) NLO ile hastalık aktivitesi ve şiddeti arasındaki ilişki incelendiğinde korelasyon saptanmadı (aktivite için: r:-0,212, p: 0,370 ve şiddet için r: -0,223, p: 0,344, sırasıyla). NLO ile Grup 1 ve Grup 2'deki hastaların ESH ve C-RP değerleri arasındaki ilişki incelendiğinde Grup 1'de ESH için: r:0,358, p:0,122 ve C-RP için r:0,634, p:0,03, Grup 2'de ESH için: r:-0,214, p:0,365 ve C-RP için r:-0,067, p:0,779.

NLO’nun kadın-erkek cinsiyet arasındaki farkı değerlendirildiğinde 3 grupta da fark olmadığı saptandı (p:0,448, p:0,554 ve p:0,082, sirasiyla).

\section{Tartışma}

Çalışmamızda NLO'nuntrombozu olan Behçet hastalarında mukokutanöztutulumlu veya sağlıklı kontrollere göre artmış olduğunu gösterdik. Ancak NLO ile hastalık aktivite ve şiddeti, cinsiyet, ESH arasında bir ilişki saptanmadi. Trombozu olan hastalarda ise C-RP ile korelasyon saptandi. Hammad ve ark tarafindan yapılan 23 hastalık bir çalışmada vasküler tutulumu olan Behçet hastalarında (n:6) yüksek NLO saptanmış ancak hasta sayısının az olması bunu istatiksel anlama kavuşturmamıştır (9). Bizim çalışmamızda 20 kişiden oluşan vaskülertutulumlu Behçet hastalarında NLO, mukokutanöztutulumlu Behçet hastalarından ve kontrol grubundan yüksek saptanmış olup fark istatistiksel olarak anlamlı saptanmıştır. 
Daha önce yapılmış olan çalışmalarda, çalışmamıza benzer şekilde BDCAF ile hastalık aktivitesi hesaplanıp hastalık aktivitesi ile NLO arasında ilişki saptanmışken biz çalışmamızda bu ilişkiyi gösteremedik (10). Bu durum hasta sayımızın nispeten az olmasından kaynaklanabilir. Benzer şekilde Nazik ve ark tarafindan yapılan çalışmada da klinik olarak aktif olduğu saptanan hastaların NLO'larının daha yüksek olduğu saptanmıştır (11). Yolbas ve ark tarafından yapılan çalışmada ise nöroBH'da ve aktif hastalığı olanlarda diğerlerine göre daha yüksek NLO değerleri saptanmıştır (12). Akkurt ve ark tarafindan yapılan çalışmada da üveiti olan BH değerlendirilmiş ve aktif hastalığı olanlarda NLO'nun yüksek olduğu saptanmıştır (13).

Ying ve ark tarafindan Behçet hastalarında yapılan bir çalışmada (10), ESH ve yüksek duyarlıklı-C-RP ile NLO arasında korelasyon saptandığı bildirilmiştir. Bizim çalışmamızda ise vasküler tutulumu olan hasta grubunda C-RP ile NLO arasinda korelasyon saptandı. İnflamasyon sürecinde hızlı artı̧̧ gösteren bir akut faz reaktanı olan C-RP ile NLO arasında ilişki saptanmış olması NLO'nun bir aktivite göstergesi olarak kullanılabileceğine işaret etmektedir. Ancak biz ESH ile NLO arasında bir ilişki saptayamadık, ESH'nın daha uzun sürede yükselmesi ve NLO'nun hastalık aktivitesi ile de korelasyon gösterememiş olması bunu açıklayabilir.

Cinsiyet ile NLO arasında her 3 grupta da ilişki saptanmadı, bu da daha önce farklı hasta gruplarında yapılan çalışma sonuçlarına benzerdi $(8,14)$.

Çalışmamızda NLO'nuntrombozu olan Behçet hastalarında mukokutanöztutulumlu veya sağliklı kontrollere göre artmış olduğunu gösterdik. Ancak NLO ile hastalık aktivite ve şiddeti arasında bir ilişki saptamadık. Bunun önemli bir nedeni hasta sayısının az olması olabilir. Çalışmamızın bazı kısıtlılıkları vardır, bunlar; hasta sayısının az olması, retrospektiftasarımı, takip süreleri sonucunda NLO değişiminin çalışılmış olmamasıdır. Özetle, NLO, kolay hesaplanabilir bir inflamatuar belirteçtir; ancak hangi durumlarda nasıl kullanılacağı konusunda hala soru işaretleri vardır. Önceki çalışmalarda da belirtildiği gibi Behçet hastalığı gibi spesifik bir laboratuar göstergesi olmayan durumlarda artmış inflamasyon veya hastalık aktivitesini değerlendirmede faydalı olabilir (15). Behçet hastalarında yüksek çıkması halinde vasküler sorunlar açısından değerlendirme yapılabilir, ancak klinik pratikte kullanımı için daha kapsamlı çalışmalara ihtiyaç vardır. 
1. Yazici H, Seyahi E, Hatemi G, et al. Behçet syndrome: a contemporary view. Nat Rev Rheumatol. 2018;14:10719

2. Balkarli A, Kucuk A, Babur H, et al. Neutrophil/lymphocyteratio and mean platelet volume in Behçet's disease. Eur Rev Med Pharmacol Sci. 2016;20:3045-50

3. Zeb A, Khurshid S, Bano S, et al. The Role of theNeutrophil-to-Lymphocyte Ratioand Platelet-to-LymphocyteRatio as Markers of Disease Activity in AnkylosingSpondylitis. Cureus. 2019;29;11:e6025.

4. Bilen Y, Cankaya E, Bilen N, et al. Increasedneutrophiltolymphocyteratio (NLR) is a sign of disease activity in systemiclupuserythematosus patients withrenalinvolvement. Nephrol Dial Transplant. 2015, 30:435-40.

5. $\mathrm{Fu} \mathrm{H}$, Qin $\mathrm{B}, \mathrm{Hu} \mathrm{Z}$, et al.:Neutrophil-andplatelet-to-lymphocyteratiosare correlated with disease activity in rheumatoid arthritis. ClinLab. 2015; 61:269-73

6. International Study Group for Behcet's disease. Criteria for diagnosis of Behcet'sdisease. International StudyGroup for Behcet'sdisease. Lancet 1990; 335:1078-80

7. Bhakta BB, Brennan P, James TE, et al. Behçet'sdisease: evaluation of a newins trumentto measure clinicalactivity. Rheumatology (Oxford). 1999;38:728-33

8. Neves FD, Caldas CAM, Medeiros DMD et al. Cross cultural adaptation of simplified version (s) of Behçet's Disease Current Activity Form (BDCAF) and comparison between two different instruments with Brazilian versions fore valuating Behçet's Disease Activity: BR-BDCAF and BR-BDCAF (s). RevBrasReumatol. 2009;49:20-31

9. Hammad M, Shehata OZ, Abdel-Latif SM, et al. Neutrophil/lymphocy teratio and platelet/lymphocyteratio in Behçet's disease: whichand when touse? Clin Rheumatol. $2018 ; 37: 2811-17$.

10. YingJiang, MingcuiZang, ShanshanLi. Serum PLR and LMR in Behçet's disease: Can they show the diseaseactivity? Medicine (Baltimore) 2017; 96: e6981

11. Nazik H, Nazik S, Çoban FG. The Importance of Neutrophilto Lymphocyteand Plateletto Lymphocyte Ratios in Active BehcetDisease. Bozok Med J 2016;6:33-6. 12. Yolbas S, Yıldırım A, GozelN,et al. HematologicalIndices May Be Useful in theDiagnosis of Systemic Lupus Ery them atosusand in Determining Disease Activity in Behçet's Disease. Med Princ Pract. 2016;25:51016.
13. Akkurt ZM, Türkçü FM, Uçmak D et al.. Behçet Hastalığında Artmış Nötrofil / Lenfosit Oranı. KÜ Tıp Fak Derg. 2014; 16: 4-11.

14. Zunni Z, Qisheng S, Liqian Z, et al. Diagnosticvalue of hemoglobin and neutrophil-to-lymphocyteratio in Behcet Disease Medicine (Baltimore) 2019; 98(52).

15. Acikgoz N. The Neutrophil-Lymphocyte Ratioand Behcet Disease.Angiology 2016;67:297. 